\title{
Tectônica em edifícios reabilitados na Obra de Norman
} Foster

\author{
Tectonics in rehabilitated buildings in the work of Norman Foster \\ Tectónica en edificios rehabilitados en el trabajo de Norman Foster
}

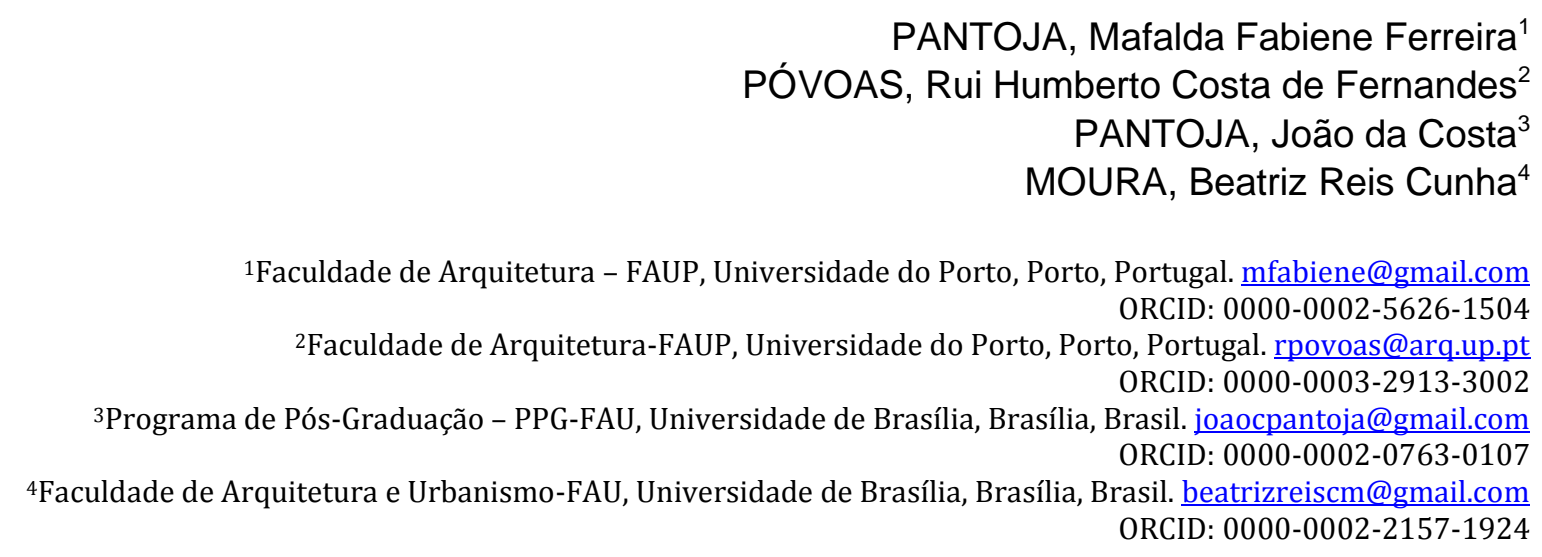

Recebido em 06/05/2020 Aceito em 15/05/2020 


\title{
Resumo
}

Pensar a cidade contemporânea como um organismo vivo e dinâmico, que necessita de respostas às demandas atuais se faz necessário e urgente. Os arquitetos, engenheiros e planejadores discutem, cada vez mais, as dinâmicas sociais, ambientais e econômicas em um contexto integrado. O presente trabalho apresenta a teoria tectônica, alicerçada em um tripé analítico composto pela: concepção, materialidade e técnica, a fim de ser aplicada como metodologia operativa para leitura e identificação do processo de projeto voltado à reabilitação de edifícios no contexto urbano. Inicialmente, buscar-se-á identificar como os parâmetros da vertente tectônica na arquitetura, alicerçada no tripé mencionado, podem servir de base interpretativa para intervenções em edifícios urbanos, com olhar voltado também para as questões tecnológicas sustentáveis que permeiam o discurso na contemporaneidade. Posteriormente, a metodologia será aplicada em estudos de casos de edifícios reabilitados e requalificados na obra do arquiteto Norman Foster. O objetivo é averiguar se os exemplos respondem às questões urbanas contemporâneas voltadas à defesa do patrimônio, preservação, reabilitação, e atendimento às preocupações das gerações futuras. Busca-se como resultado, a identificação da tectônica como ferramenta do projeto multidisciplinar, com foco na reabilitação do patrimônio, em um campo emergente que alie e respeite passado, presente e futuro.

Palavras-Chave: Tectônica / Norman Foster / Reabilitação / Patrimônio / Arquitetura Contemporânea

\begin{abstract}
Thinking about the contemporary city as a living and dynamic organism that needs answers to current demands is necessary and urgent. Architects, engineers and planners increasingly discuss social, environmental and economic dynamics in an integrated context. The present work presents the tectonic theory, based on an analytical tripod composed by: conception, materiality and technique, in order to be applied as an operational methodology for reading and identifying the design process aimed at the rehabilitation of buildings in the urban context. Initially, it will try to identify how the parameters of the tectonic aspect in architecture, based on the mentioned tripod, can serve as an interpretive basis for interventions in urban buildings, with a focus also on the sustainable technological issues that permeate the discourse in contemporary society. Subsequently, the methodology will be applied in case studies of buildings rehabilitated and requalified in the work of architect Norman Foster. The objective is to find out if the examples answer contemporary urban issues aimed at the defense of heritage, preservation, rehabilitation, and pointing out the concerns of future generations. As a result, the search for the identification of tectonics as a tool of the multidisciplinary project, focusing on the rehabilitation of heritage, in an emerging field that combines and respects the past, present and future.
\end{abstract}

Key-Words: Tectonics / Norman Foster / Rehabilitation / Patrimony / Contemporary Architecture

\section{Resumen}

Pensar en la ciudad contemporánea como un organismo vivo y dinámico que necesita respuestas a las demandas actuales es necesario y urgente. Arquitectos, ingenieros y planificadores discuten cada vez más las dinámicas sociales, ambientales y económicas en un contexto integrado. El presente trabajo presenta la teoría tectónica, basada en un trípode analítico compuesto por: concepción, materialidad y técnica, para ser aplicada como metodología operativa para la lectura e identificación del proceso de diseño dirigido a la rehabilitación de edificios en el contexto urbano. Inicialmente, trataremos de identificar cómo los parámetros del aspecto tectónico en la arquitectura, basados en el trípode mencionado, pueden servir como base interpretativa para intervenciones en edificios urbanos, con un enfoque también en los problemas tecnológicos sostenibles que impregnan el discurso en los tiempos contemporáneos. Posteriormente, la metodología se aplicará en estudios de caso de edificios rehabilitados y recalificados en el trabajo del arquitecto Norman Foster. El objetivo es averiguar si los ejemplos responden a problemas urbanos contemporáneos destinados a la defensa del patrimonio, la preservación, la rehabilitación y la satisfacción de las necesidades de las generaciones futuras. Se busca como resultado la identificación de la tectónica como herramienta del proyecto multidisciplinario, enfocado en la rehabilitación del patrimonio, en un campo emergente que combina y respeta el pasado, el presente y el futuro.

Palabras clave: Tectónica / Norman Foster / Rehabilitación / Patrimonio / Arquitectura contemporánea 


\section{Introdução}

\subsection{O caminho da tectônica}

A temática da tectônica originou-se em meados do século XIX, período de intenso debate arquitetônico ocasionado por mudanças relevantes na sociedade, como as expedições arqueológicas do século XIX, o emprego de conhecimentos da física nas edificações, utilização de novo repertório de materiais, ligações e vínculos, consequente surgimento de novas tecnologias. Esses acontecimentos não só estimularam o homem no entendimento do passado, por meio das produções artísticas teóricos interessavam-se progressivamente pela busca da compreensão da sociedade. Da mesma maneira, a arquitetura caminhava na busca por esse entendimento, a partir da teoria tectônica e do processo construtivo aplicado à essas obras, pois este mesmo processo construtivo não só intencionalmente agregava significado à obra, como também, relacionava-se com a cultura construtiva do local, em que se manifestavam valores, aspectos técnicos e culturais.

A consolidação do conceito de tectônica como se conhece na atualidade deve-se principalmente pelas publicações feitas Karl Bötticher (1852). Estas coincidem com o período em que houve a dissociação entre arquitetura e engenharia, esta última, extremamente imersa em métodos construtivos oriundos do cenário da revolução industrial. Nas publicações de Bötticher (1852) ele utiliza duas esferas articuladas para compreensão da arquitetura, sendo o kernform, forma ou núcleo construtivo e funcional e o kunstform, superfície da edificação, forma aparente. Sendo de responsabilidade da tectonik a articulação entre esses dois âmbitos. Além disso faz uso do ferro na arquitetura, inovação que auxilia na aceitação de novos materiais presentes no processo construtivo.

Teóricos como Müller (1830), Gottfried Semper (1851) e Karl Bötticher (1852), nesse período de intensas mudanças, articulam a partir da tectônica a estrutura formal e a estrutura resistente, ou seja, a correlação entre as proporções e arranjos oriundos dos arquétipos tradicionais, e a nova lógica das propriedades dos materiais e dos cálculos, respectivamente.

Após a organização do conceito de tectônica estabelecida por Bötticher (1852), Gottfried Semper (1851) o transpõe para seu contexto industrial de novos materiais, estabelecendo uma relação da arquitetura e sua materialidade. Em seus estudos Semper possui a preocupação em explicar a origem da arquitetura e o desenvolvimento histórico dos povos por influência das expedições arqueológicas dos séculos XIX. Busca, portanto, entender essa origem através da relação da arquitetura com sua materialidade, já que como dito a arquitetura pode expressar muito em sua essência construtiva, as características de um povo, o clima e a disponibilidade de recursos.

Ao final do século XIX a teoria da tectônica cai em desuso, pois com as vanguardas o protagonismo expressivo cabia à geometria das superfícies, sendo secundária a expressão material. Este período foi de relevância para o movimento moderno, pois esta geometria das superfícies permitiu ruptura com as tradições e surgimento de novos princípios construtivos que serviram de influência para pioneiros do modernismo.

No século XX, a temática é retomada por teóricos como Peter Collins (1960), em seu artigo Tectonics, o autor que explora a história do concreto armado e une a técnica ao domínio criativo. Posteriormente, Sekler em Structure, Construction, Tectonics (1965), resgata o conceito de herança cultural. É propriamente no final do século $\mathrm{XX}$, com o intenso debate sobre a retomada da tectônica na arquitetura, que Kenneth Frampton aparece como protagonista. Em sua obra Studies in Tectonic Culture (1995), Frampton reestabelece bases para aplicação da teoria tectônica na atualidade, tendo em vista sua contraposição às vertentes pós-modernas cenográficas que apresentavam uma arquitetura desvinculada de sua unidade estrutural. Frampton considera recíproca a relação entre construção formal da arquitetura e concepção técnico-construtiva, ademais estabelece relação entre 
estrutura e herança cultural.

A ampla gama de conceitos e metodologias que abordam a tectônica na arquitetura, tem sua evolução influenciada pelas diversas compreensões desenvolvidas por diferentes teóricos e nascidas em contextos sociais, econômicos e culturais distintos. Todos conduzem a teoria de forma a evidenciar aspectos como função, tipo, relação com o todo, materialidade, entre outros, sempre de forma a conectar a arquitetura à construção. A construção, por sua vez, é expressa pela criação (concepção) e pelo saber-fazer, estabelecido pela ação humana sobre um objeto a partir do emprego do seu intelecto.

Tectônica relaciona-se também diretamente às definições acerca de herança cultural ao sinalizar valores de uma sociedade através de sua materialidade e o intelecto humano pelas técnicas utilizadas. São reflexões que buscam entender a realidade tecnológica e industrial dos materiais e dos processos construtivos, a partir da investigação sobre a forma de construção reveladas pelas civilizações passadas. Essas reflexões geram na contemporaneidade o senso acerca da importância da dimensão simbólica quanto à preservação e restauração.

A teoria tectônica segue seu curso ao longo do século XX correlacionando a arquitetura com o saberfazer, com as técnicas construtivas e com a relevância da cultura e da herança, chegando ao século XXI um tanto amadurecida e retomando seu lugar no debate acadêmico por meio de diversos autores. Segundo Aristótoles Cantalice II, em sua tese "Descomplicando a Tectônica" (2015), o autor retoma os aspectos relacionados à poética da construção e metodologicamente estabelece um "tripé de análise". Este tripé teria a teoria tectônica alicerçada por três esferas (Figura 1) que formam a base deste tripé. São elas: a concepção, a materialidade e a técnica. A concepção trata-se do ato de conceber o conceito do projeto e leva em consideração necessidades pragmáticas, herança cultural, características climáticas do sítio e recursos materiais disponíveis, que, segundo Edson Mahfuz (1995), ao segui-los, seria possível alcançar a experiência criativa, já que o conceito guia o processo de criação da obra. A materialidade diz respeito às propriedades intrínsecas do material como peso, dureza, extensão, cor aspereza, entre outros. Já a técnica diz respeito à arte da fabricação, e ao processo em que o homem controla e direciona as forças da natureza para seu próprio benefício, podendo ser a expressão que revela o tipo de homem e de uma comunidade, por conta da herança construtiva que abarca.

Figura 1: Tripé de análise

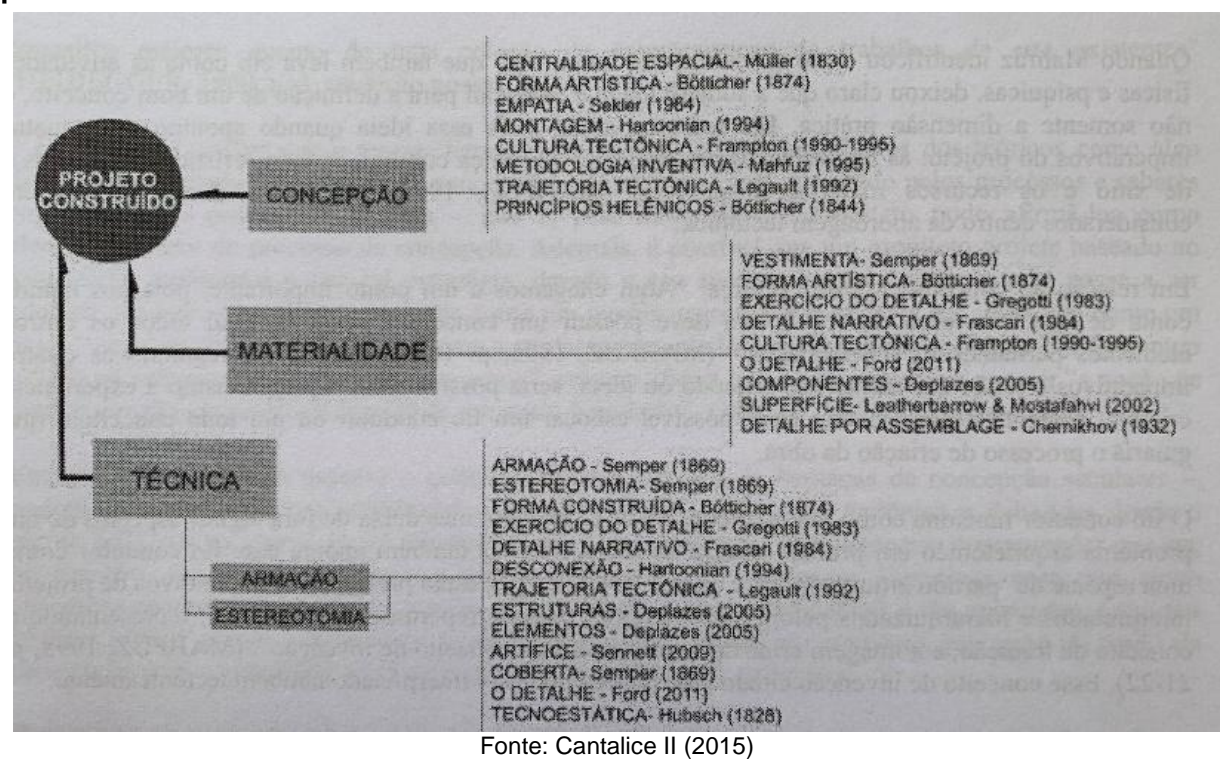


A tectônica não poderia estar dissociada das questões de sustentabilidade ou aspectos bioclimáticos, uma vez que a matéria prima disponível é determinante para a expressão arquitetônica, assim como a forma de construir pode influenciar diretamente no conforto higrotérmico, acústico e luminoso de uma edificação. Assim, as tecnologias sustentáveis podem corroborar para a sustentabilidade social, econômica e ambiental.

No contexto contemporâneo, onde a questão ambiental é uma constante preocupação ao considerar a agravante situação do planeta quanto à escassez de recursos, a ideia de preservação torna-se cada vez mais importante no debate acerca da arquitetura. Dessa forma, a teoria tectônica pode ser utilizada como forma de otimização de recursos e resgate à herança cultural.

O presente artigo busca, com base no referencial teórico acerca da teoria tectônica e na metodologia de distribuição dos conceitos da teoria no "tripé" anteriormente elucidado, analisar dois projetos do arquiteto inglês Norman Foster voltados para o contexto da reabilitação e restauração, com ênfase nas abordagens tecnológicas sustentáveis na contemporaneidade.

\subsection{Norman Foster, um arquiteto completo}

Norman Foster é um arquiteto inglês conhecido por suas obras high tech e sua constante preocupação com o meio ambiente expressa em seus projetos. Recebeu inúmeros prêmios, incluindo o Pritzker, em 1999. Fundou o escritório Foster+Partners, atualmente um dos maiores escritórios de Arquitetura e Urbanismo do mundo. Em suas obras o reconhecimento não é apenas estético, mas também por suas soluções estruturais arrojadas e complexas, pois em seu processo criativo a tecnologia está sempre presente. Foster afirma que em nenhum momento na história da construção é possível desconsiderar a tecnologia, por considerá-la fundamental para a criação dos espaços.

A reabilitação, a preocupação com a vida útil do edifício, e o estudo da herança cultural e simbólica deste, também são constantes na projetação de Foster, pois o mesmo costuma utilizar e enaltecer elementos característicos do local em seu projeto, a fim de ressaltar a importância de aspectos como: topografia, cultura local, integração da arquitetura e estrutura, materiais empregados e tecnologia sustentável.

Norman Foster encara como preceito fundamental ao ato de projetação o aspecto constantemente mutável da contemporaneidade. Foster declara: "a única constante é a modificação", ainda: "A arquitetura não está contida em um campo específico, mas em cada ato humano de transformação". Assim, pensa e concebe sua arquitetura aberta à possibilidade de mudanças, transformações e adequações em face à uma sociedade dinâmica e em constante mudança. Portanto, pensa sua arquitetura como elemento vivo. Sua obra expressa claramente tal vertente em diversos exemplos como o Reichstag (Figura 2) ou o Great Court do Museu Britânico (Figura 3). Em ambos exemplos, as dinâmicas sociais, ambientais e econômicas se encontram em um contexto integrado, de forma resolutiva e operativa, capazes de associar a tectônica de sua concepção estrutural como via de alcance às soluções sustentáveis, belas e autênticas. 
Figura 2: Reichstag

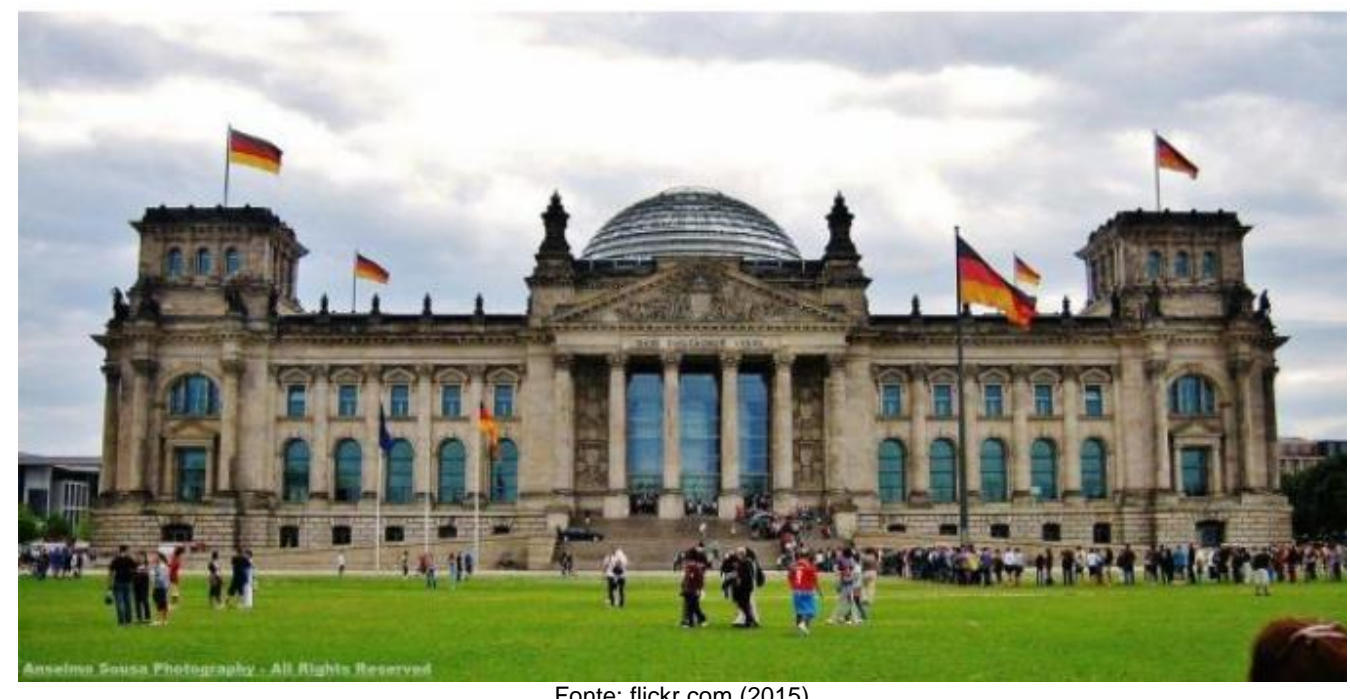

Figura 3: Smithsonian Institution Courtyard.

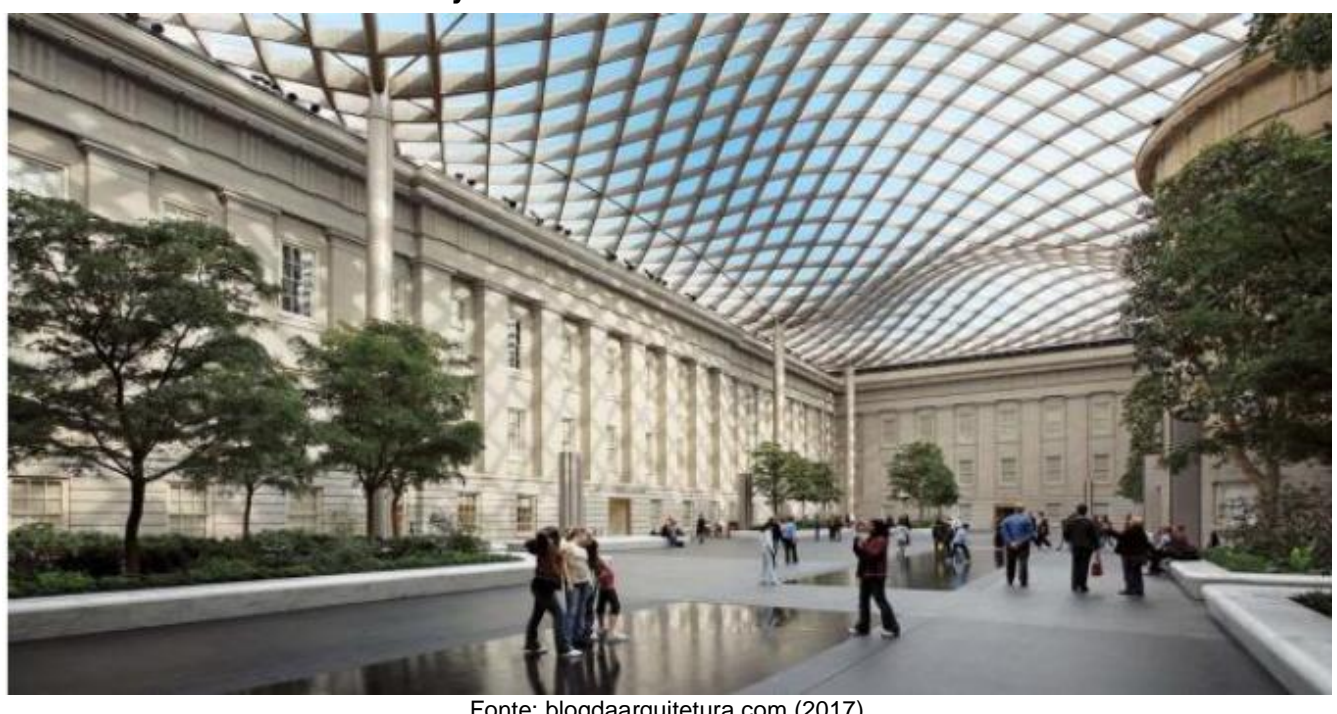

Dessa maneira, o presente artigo, focará na seleção de duas obras do arquiteto Norman Foster, a fim de elucidar os parâmetros tectônicos voltados à preservação de edifícios. Para tal, os edifícios selecionados demostram as suas respectivas relações com o patrimônio edificado em contextos urbanos distintos, a fim de se permitir maiores perspectivas de análise em defesa do patrimônio, da preservação e preocupações sustentáveis. Com alicerce no "tripé da tectônica", serão estudadas as edificações: Apple Carnegie Library, em Washington e Apple Champs Élysées, em Paris, com foco na identificação dos aspectos em que a tectônica foi utilizada como ferramenta que associa diversas áreas de conhecimento à manutenção e reabilitação do patrimônio, destacando a tecnologia e a sustentabilidade, e a maneira que estas obras evidenciam o respeito à sociedade passada, presente e futura.

\section{Apple Carnegie Library}

O Apple Carnegie Library (Figura 4) localiza-se no coração de Washington DC, surgiu de uma revitalização de um significativo monumento para a cidade, que passou por um período de negligência e desuso. $O$ interesse pela preservação do monumento deu-se pela busca por lugares emblemáticos em que a Apple procura abrir suas lojas e a herança cultural que o mesmo representava para a população local, já que desde sua abertura em 1903 desempenhou papel importante na vida desses cidadãos por ter sido a primeira biblioteca pública da cidade. 
Figura 4: Apple Carnegie Library.

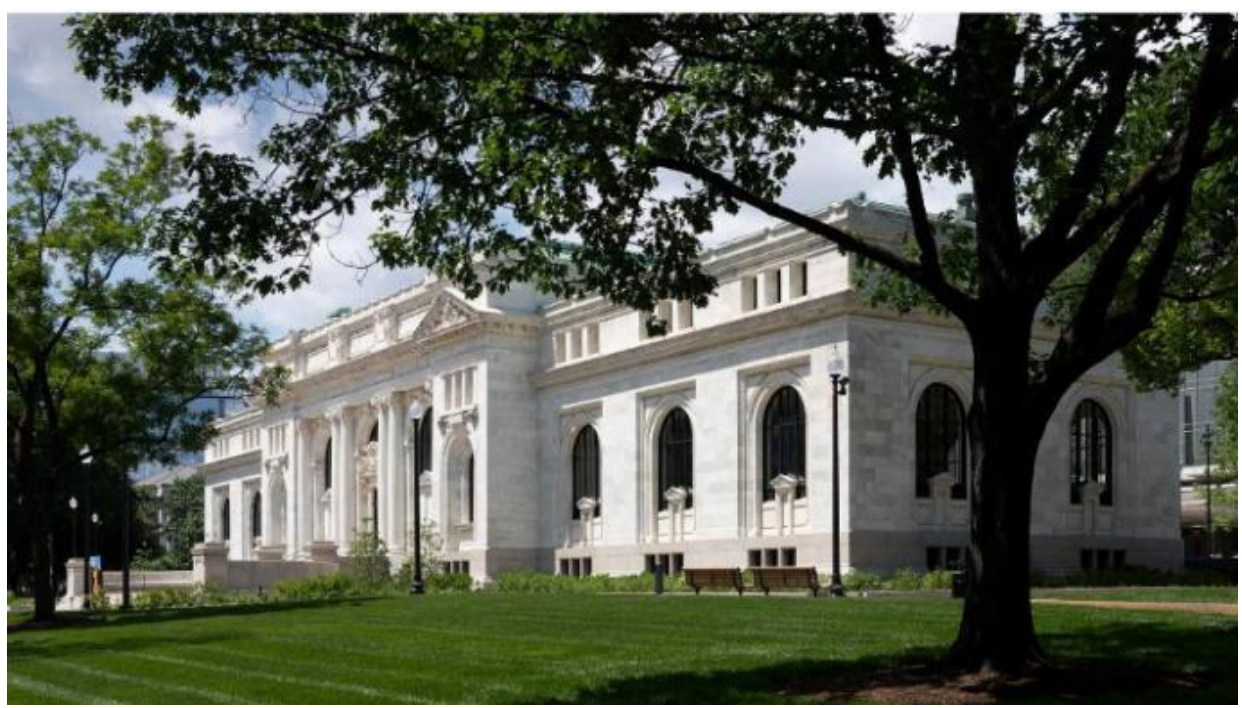

Fonte: fosterandpartners.com (2019)

\subsection{A concepção}

A carga histórica do edifício e a modernidade de sua ressignificação foram pontos de partida para a concepção da obra, uma vez que estes pontos deveriam estar em equilíbrio entre si. Desse modo, o edifício possui entradas no eixo norte e sul (Figura 5) que convida a rota urbana ao interior do edifício, sendo a entrada sul a original do edifício com uma escadaria de três andares, ambiente também destinado a eventos públicos. O centro do edifício dedica-se à uma área de diversão e interação de especialistas de diversas áreas, apresenta pé direito duplo e coberto por uma nova claraboia (Figura 6) que traz luz natural ao interior, onde o público pode observar as atividades realizadas do mezanino. No segundo andar uma grande escadaria leva ao centro histórico, onde é exposta a história e origem do edifício, o porão também se dedica ao valor histórico do edifício com fotos e documentos.

Figura 5: Apple Carnegie Library.

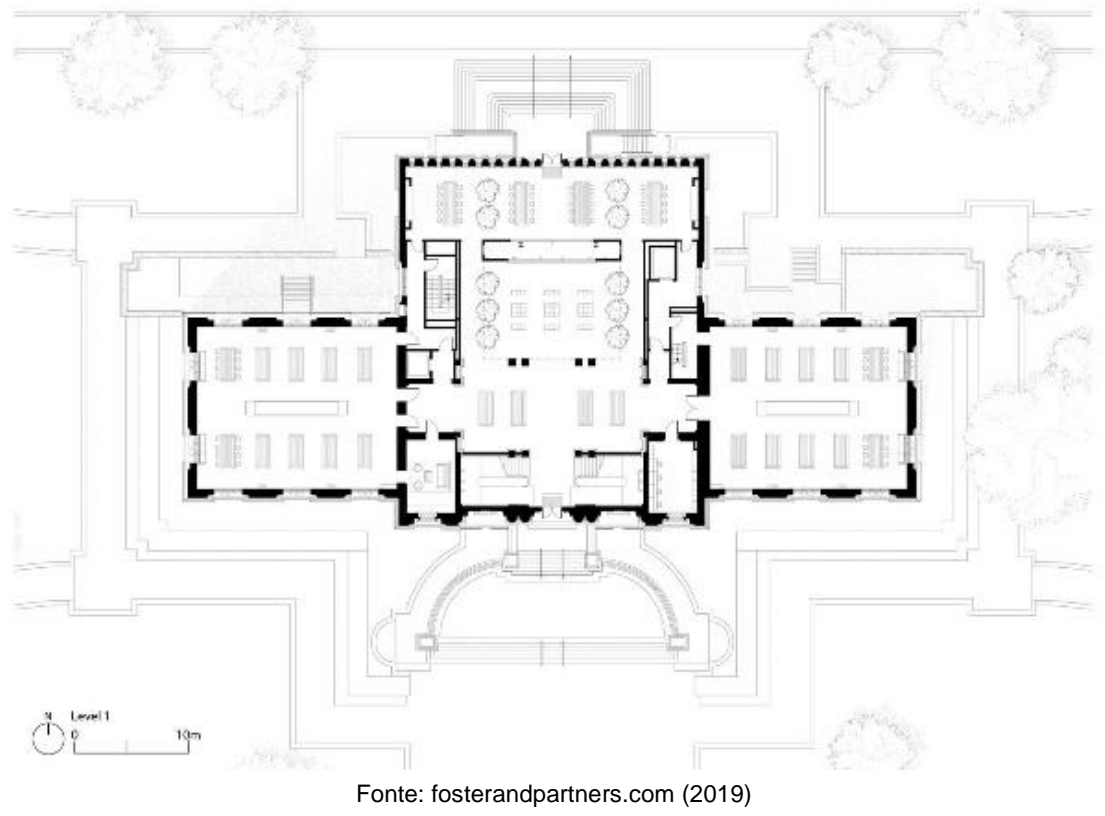


Figura 6: Apple Carnegie Library.
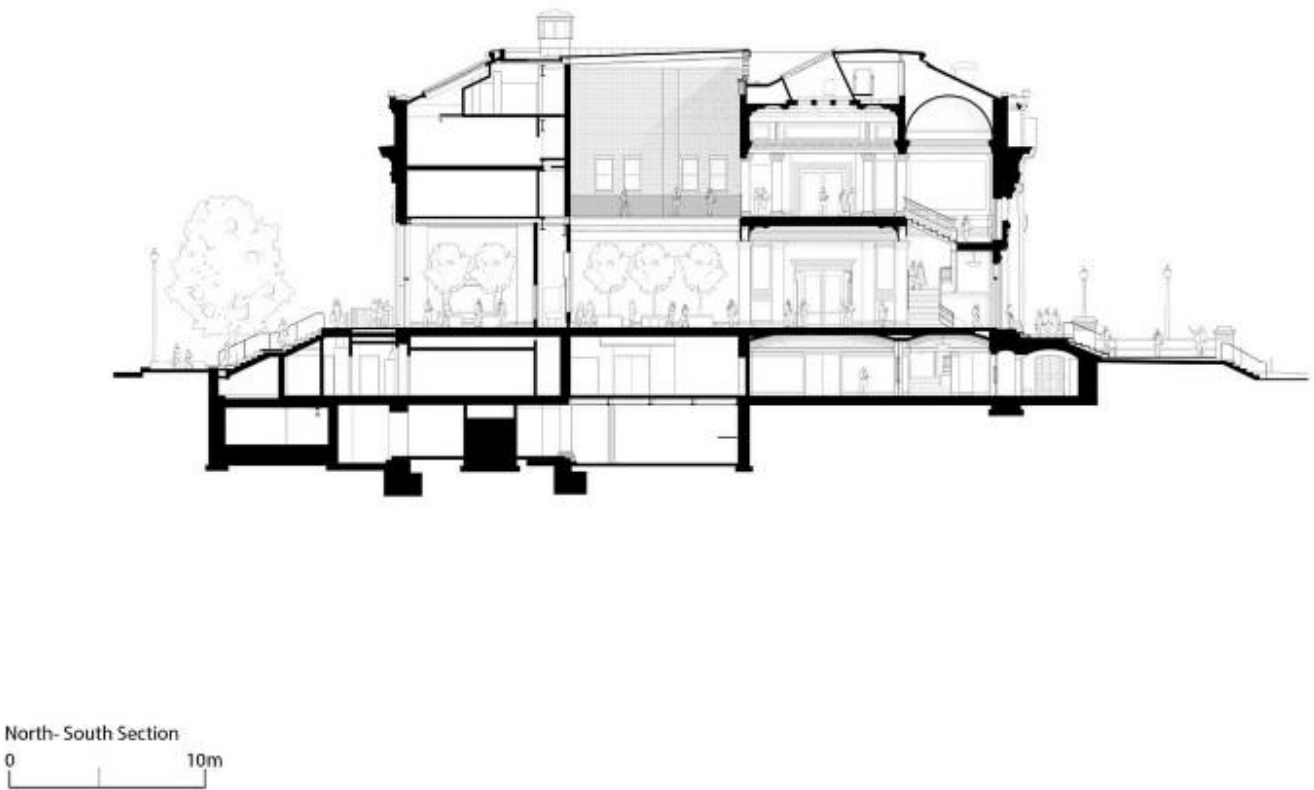

Fonte: fosterandpartners.com (2019)

Portanto, o projeto em sua concepção, com objetivo de revitalizar não só fisicamente o edifício, propõe modernidade e vitalidade ao edifício, não desconsiderando sua herança cultural e significado para a população local. Pode-se afirmar que a base conceitual da concepção está fortemente ligada à ressignificação e preservação da obra.

\subsection{A materialidade}

Desde o início da concepção da revitalização do edifício, em que o fator histórico é cuidadosamente trabalhado e estudado no processo, a materialidade também foi cuidadosamente proposta e alcançada por meio dos aspectos sensoriais ou das características intrínsecas ao material empregado (como dureza, cor, extensão, aspereza...), e foi também responsável pela manutenção memória da edificação.

O edifício é originalmente projetado e construído no estilo Beaux-Arts, o qual faz referência às formas clássicas gregas e romanas, estilo muito comum em construções públicas monumentais no período de sua construção. Essas características no Apple Carnegie Library estão presentes na fachada em pedra, nos adornos que remetem ao clássico, nas entradas cobertas com frontões triangulares (Figura 7), no corrimão em bronze, no interior com as escadas e pisos em mármore. Essa materialidade e características específicas que fazem parte do movimento Beaux-Arts, são elementos que remetem o conteúdo da arquitetura histórica e memória do edifício, e foram rigorosamente preservadas em sua revitalização como forma de resgate e valorização do passado. 
Figura 7: Frontões triangulares em mármore.

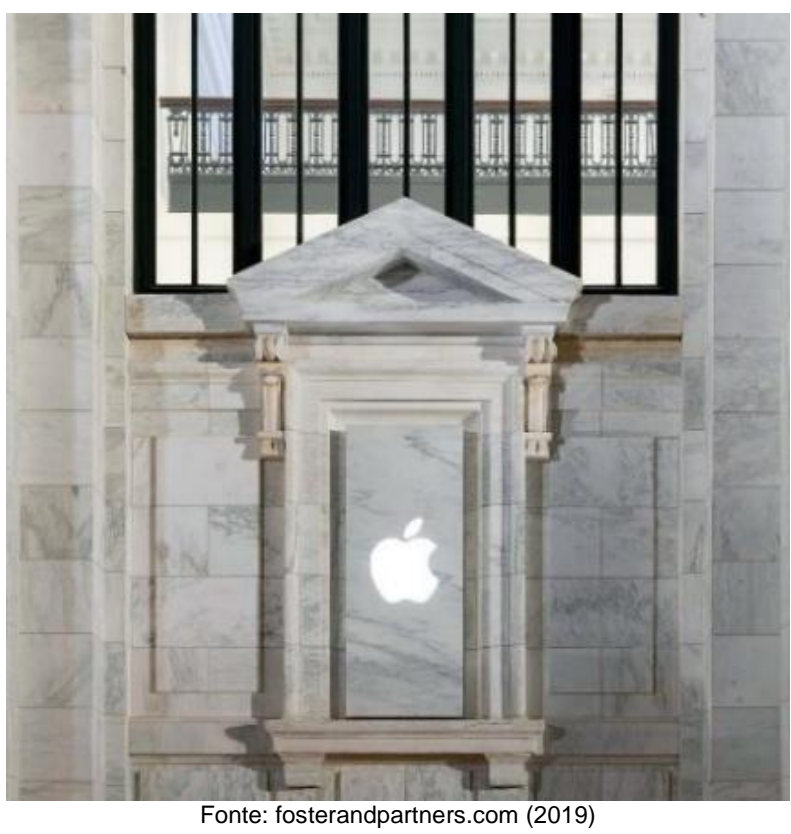

Para Deplazes (2010), "a materialidade une o todo arquitetônico, cultural e atmosférico". No edifício da Apple Carnegie Library essa afirmação é facilmente observada em função dos materiais utilizadas no interior do edifício. Pode-se observar uma propriedade da materialidade como esfera tectônica na disponibilidade dos materiais da região, logo, nas paredes do edifício, a cor branca é dada pelo mármore extraído de uma pedreira da região (Figura 8). Esta atitude de composição, não só favorece a memória e valor antigo da obra para a população, mas também, compromete-se com o uso de materiais de origem local, uma das qualidades sustentáveis no projeto.

Figura 8: Vista interna Apple Carnegie Library.

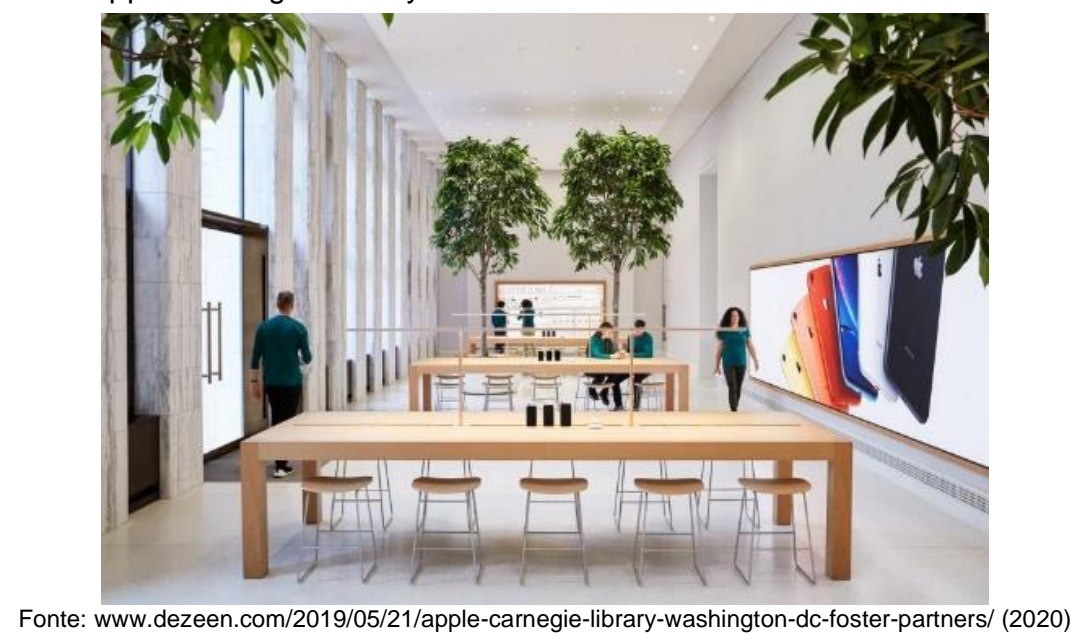

Dessa forma, os materiais preservados e revitalizados no edifício foram selecionados com objetivo de promover as mudanças necessárias e adequá-la à modernidade, adequando o ambiente histórico a que pertence.

\subsection{A técnica}

Tecnicamente a estrutura do edifício foi mantida e revitalizada de forma a agregar em um só ambiente a vitalidade do momento atual e a memória do passado. A antiga área de circulação e atendimento passou a ser um átrio aberto, uma enorme escada para o segundo andar foi restaurada para seu estilo original, assim como alguns detalhes em pedra também foram restaurados. 
$\mathrm{Na}$ tectônica, os detalhes aparecem nas reflexões de Gregotti (1983), arquiteto italiano, como o elemento técnico mais importante, pois propiciam identidade ao edifício. Logo, no Apple Carnegie Library, a restauração corrobora para que os detalhes restaurados tornem expressos a identidade e o significado da obra, tornando clara a justaposição da estrutura histórica com o design contemporâneo.

Pode-se dizer também que a edificação caminha no sentido da tectônica sustentável uma vez que apresenta preocupações e inovações acerca do consumo energético da mesma. No Apple Carnegie Library foram instaladas novas coberturas com claraboias (Figura 9) que promovem a ventilação natural nos ambientes interiores, assim como entrada generosa de luz durante o dia, reduzindo então, o consumo energético da edificação.

Figura 9: Vista interna das claraboias Apple Carnegie Library.

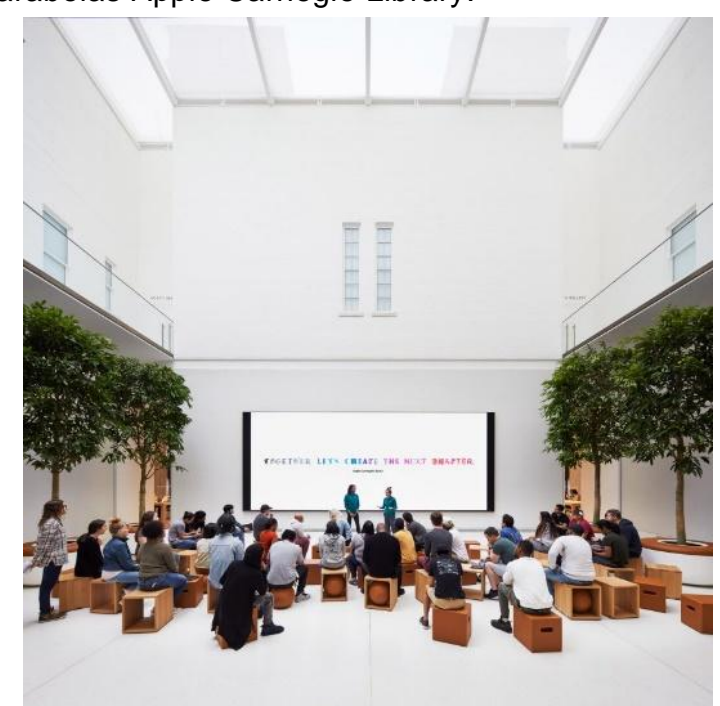

Fonte: www.dezeen.com/2019/05/21/apple-carnegie-library-washington-dc-foster-partners/ (2020)

Em resumo, o edifício da Apple Carnegie Library enquadra-se na reflexão tectônica alicerçada nas esferas da concepção, da materialidade e da técnica (Figura 10) no contexto contemporâneo, por meio da correlação dos aspectos e fatores que influenciaram os pontos importantes para a manutenção do edifício enquanto monumento histórico e, ao mesmo tempo, inserindo-o na contemporaneidade. Podese observar que a edificação em questão, ao articular as esferas da forma ou núcleo (kernform) e o núcleo construtivo e funcional (kunstform), defendidos por Bötticher (1852) há dois séculos atrás, exemplificam, em plena contemporaneidade, a articulação de ambos pela tectonik do edifício. Já a tectônica, por sua vez, não só tem sua atualização conceitual e prática na contemporaneidade, como também garante o respeito à herança cultural e utilização do edifício, anteriormente em desuso, em uma espécie de condução de nova vida da edificação e ressurgimento no tecido urbano pré-existente. 
Figura 10: Tripé de análise tectônica do Apple Carnegie Library.

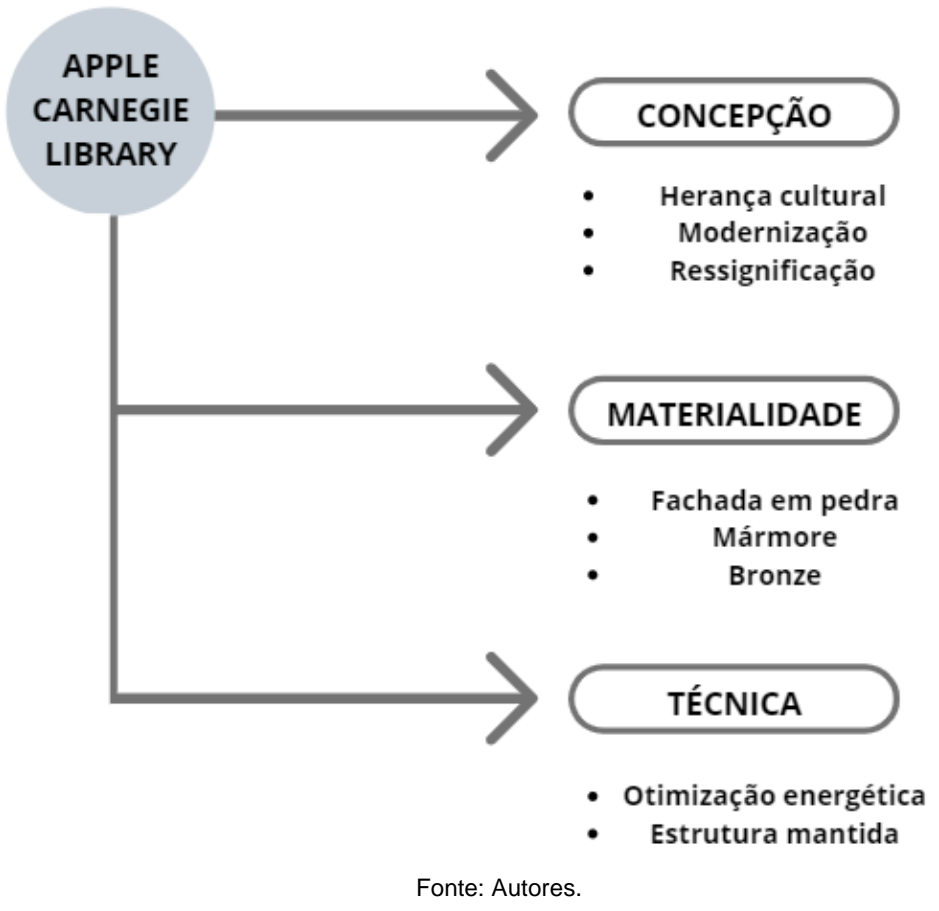

\section{Apple Champs Élysées}

Outro exemplo para a reflexão e comparação ao exemplo anterior acerca do debate tectônico voltado a edifícios reabilitados é o também edifício da Apple Champs Élysées (Figura 11). O edifício apresenta contexto de implantação já um pouco divergente em relação ao anterior, pois localiza-se na esquina da rua Champs-Élysées em Paris, uma avenida bastante conhecida e movimentada, diferentemente do contexto em que se encontra o Apple Canergie Library que, apesar de também estar inserida na malha urbana, não compartilha da mesma 'agitação locacional' em que o Apple Champs Élysées se encontra. A avenida em que o edifício se localiza é composta por edifícios com ornamentos também no estilo Beaux-Arts, que expressam o caráter atemporal da cidade.

O edifício da Apple Champs-Élysées comporta apartamentos da era Haussmann, período em que ocorreram modificações na urbanização de Paris com reformas motivadas por questões sanitárias, militares, e que buscavam embelezamento da cidade por meio de ideais de simetria na malha urbana.

Figura 11: Apple Champs-Élyssées

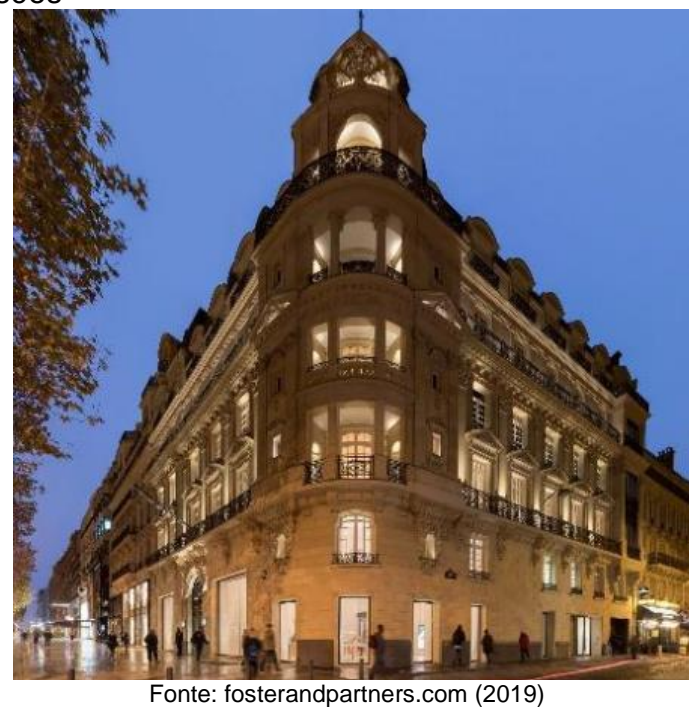




\subsection{A concepção}

Durante sua vida útil, o edifício passou por inúmeras modificações e a reabilitação proposta pela Foster + Partners visa reviver sua originalidade e captar a essência da metrópole movimentada em que se insere, ao mesmo tempo busca trazer elementos inovadores que representem não só a o padrão das lojas Apple, mas também a conjuntura contemporânea da sociedade, aliando a justaposição entre antigo e novo, numa relação mútua capaz de proporcionar uma experiência sensível única, ancorada na herança cultural, ressignificada e modernizada.

Nesse caso, a herança cultural e histórica, assim como no projeto analisado anteriormente, pautam a concepção tectônica com forte relação com o passado, mantendo, de forma cuidadosa, detalhamentos originais como molduras (Figura 12) e escadas (Figura 13) que foram restauradas, vitrais, além da consequente cautela na escolha dos materiais que compõe o espaço. A relação com o novo encontrase na ressignificação do edifício com instalações modernas e soluções estruturais que inovam no sentido estético e sustentável.

Figura 12: Apple Champs-Élyssées

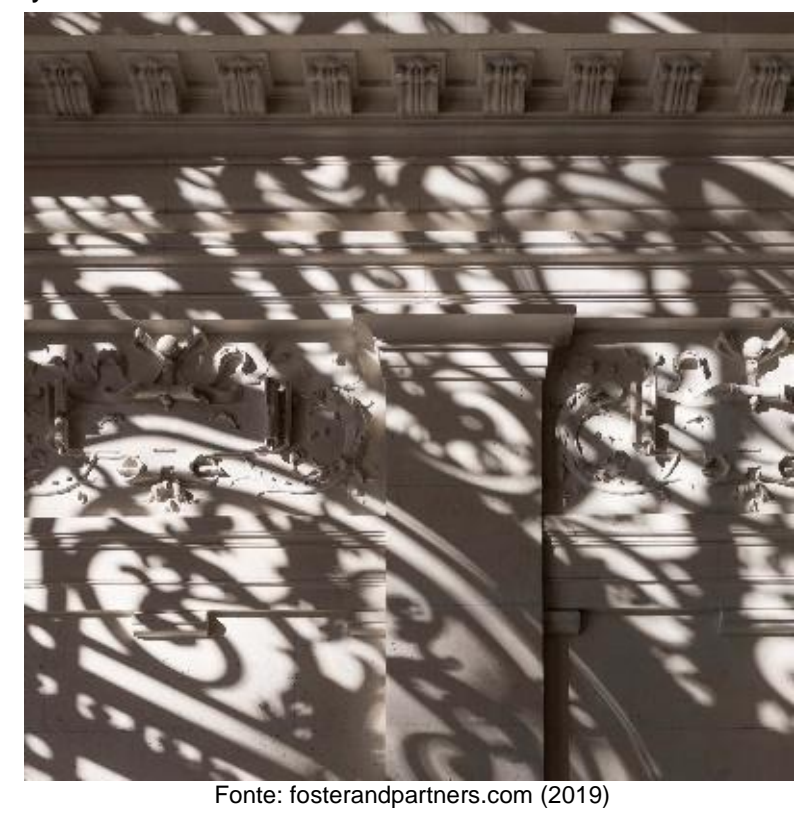

Figura 13: Apple Champs-Élyssées

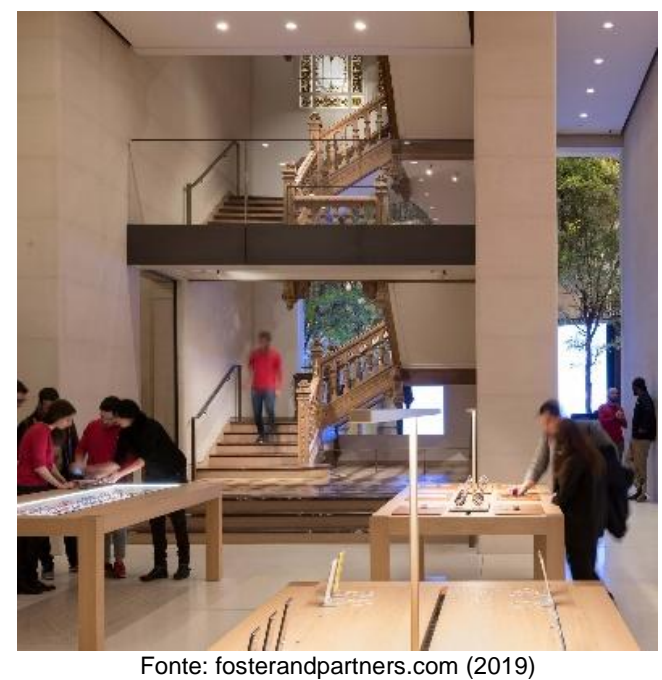

É bastante notável o processo criativo do arquiteto apoiado no equilíbrio entre respeito ao passado histórico da edificação, assim como ponte com o presente por meio das tecnologias contemporâneas, 
conferindo originalidade à releitura e reabilitação do edifício. Atualmente alimentado $100 \%$ de energia renovável, o Apple Champs-Élysées apresenta vários elementos de design ambiental.

\subsection{A materialidade}

Como mencionado anteriormente, a memória e a herança cultural na composição de uma edificação podem ser alcançadas pela sua materialidade. Para este fim, o projeto de reabilitação buscou remeter o espírito original do lugar, na forma de reapropriação do patrimônio do edifício, a começar pela inteira recuperação da fachada e da entrada do edifício e, também, por meio da cuidadosa especificação de materiais utilizados na obra.

Assim, a materialidade do edifício é expressa pela manutenção e recuperação do parquet de carvalho francês dentro dos apartamentos transformados em salas de vendas e demonstração, a pedra da Borgonha da fachada do edifício foi importada também para o interior, ladrilhos de diferentes salas foram substituídos e alguns elementos outrora destruídos foram reconstruídos, como lareiras e mármores. Tudo com fins de resgate e mescla da arquitetura histórica da edificação à modernidade, com um design que homenageia o passado e introduz espaços modernos, como o pátio interno coroado por uma clarabóia em que janelas, vitrais e varandas se misturam (Figura 14).

Figura 14: Apple Champs-Élyssées.

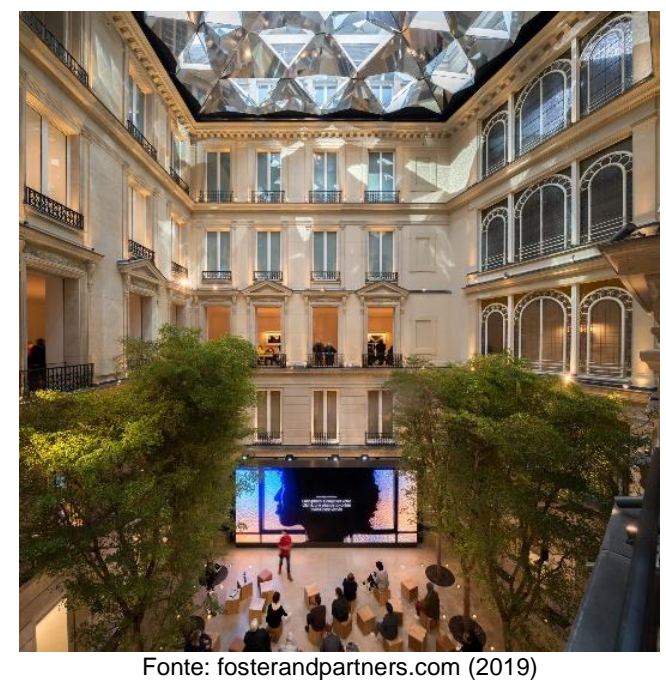

\subsection{A técnica}

Pode-se afirmar que, além do destaque técnico-construtivo empregado para restaurar diversos elementos arquitetônicos originais do edifício, assim como técnicas de recuperação de materiais, o Apple Champs-Élysées apresenta forte apelo quanto à inovação tecnológica sustentável. $\mathrm{O}$ edifício, como mencionado anteriormente, possui um 'telhado escultural' de vidro aplicado na cobertura do pátio interno que não só proporciona aproveitamento significativo da luz solar, como também, por meio dos painéis solares fotovoltaicos (Figura 15), funcionam como geradores de energia 100\% renovável e, por fim, conferem representação estética à obra uma vez que o Kaléidoscope formado reflete imagens do edifício revelando sua essência, num misto de exibição e manutenção da memória do lugar e da vida atual que pulsa em seu interior. 
Figura 15: Painéis fotovoltáicos da Apple Champs-Élysées.

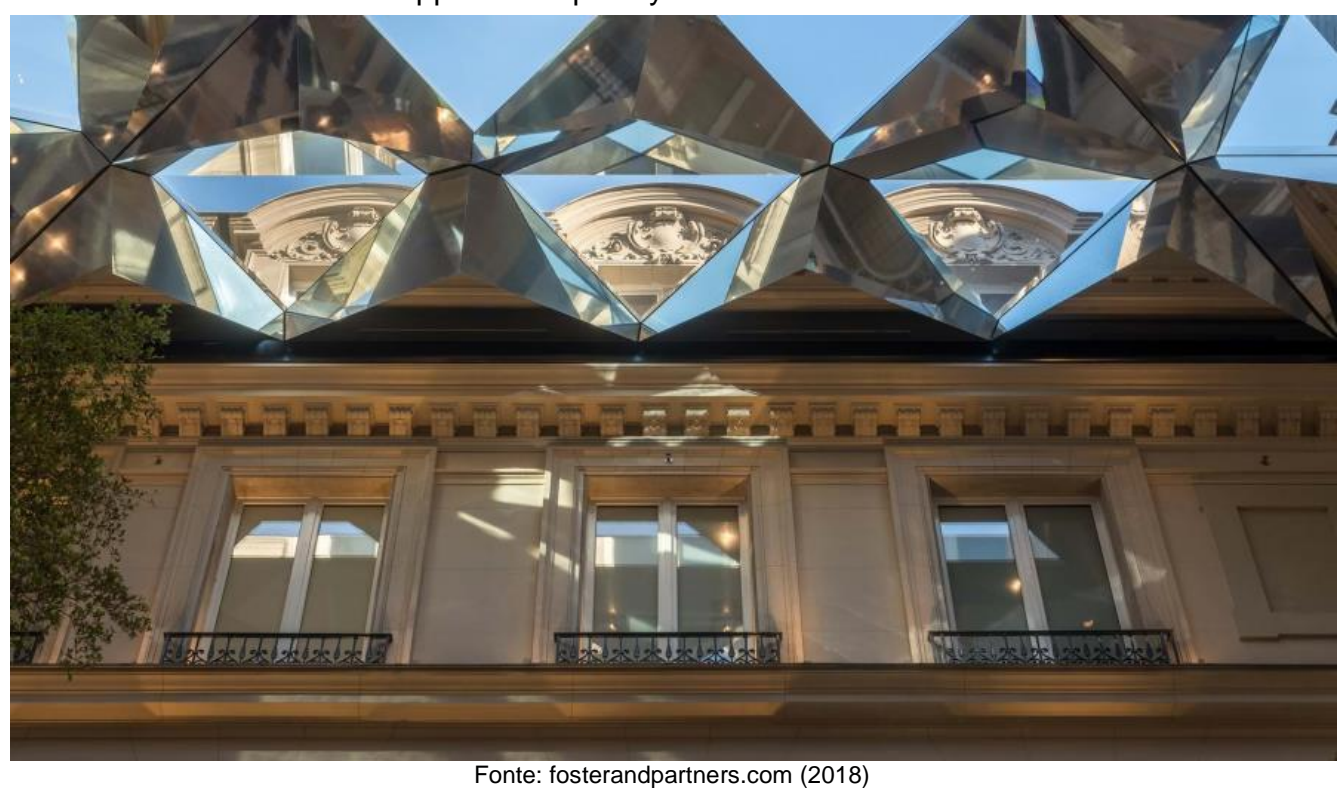

Outra solução técnica e inovadora para o edifício foi a instalação de um sistema integrado de coleta de água da chuva que é aproveitada no abastecimento dos banheiros e irrigação das árvores e paredes verdes dispostas no pátio interno.

Em resumo, pode-se afirmar que o edifício da Apple Champs-Élysées, à mesma maneira que o exemplo anterior, traduz a reflexão tectônica alicerçada nas esferas da concepção, da materialidade e da técnica (Figura 16), uma vez que seus projetos espelham a busca pela manutenção da herança cultural ao mesmo tempo que inovam em proposições espaciais adequadas à contemporaneidade e permitem que sua arquitetura flua no contexto de respeito ao passado e readequação do presente. Pode-se dizer ainda, que o edifício, ao resgatar o conceito de herança cultural trazido por Sekler (1965), ou apresentar as técnicas utilizadas na especificação dos materiais ancoradas no domínio criativo trazido por Collins (1960), não só atualizam a conceituação da tectônica na contemporaneidade com a relação entre construção formal da arquitetura e concepção técnico-construtiva trazidos por Frampton (1995) em seus estudos, mas corroboram para a relação entre estrutura e herança cultural defendida por este último, pois evidenciam os aspectos da função e da relação com o todo, interligando a arquitetura à construção. 
Figura 16: Tripé de análise Apple Champs- Élyssées

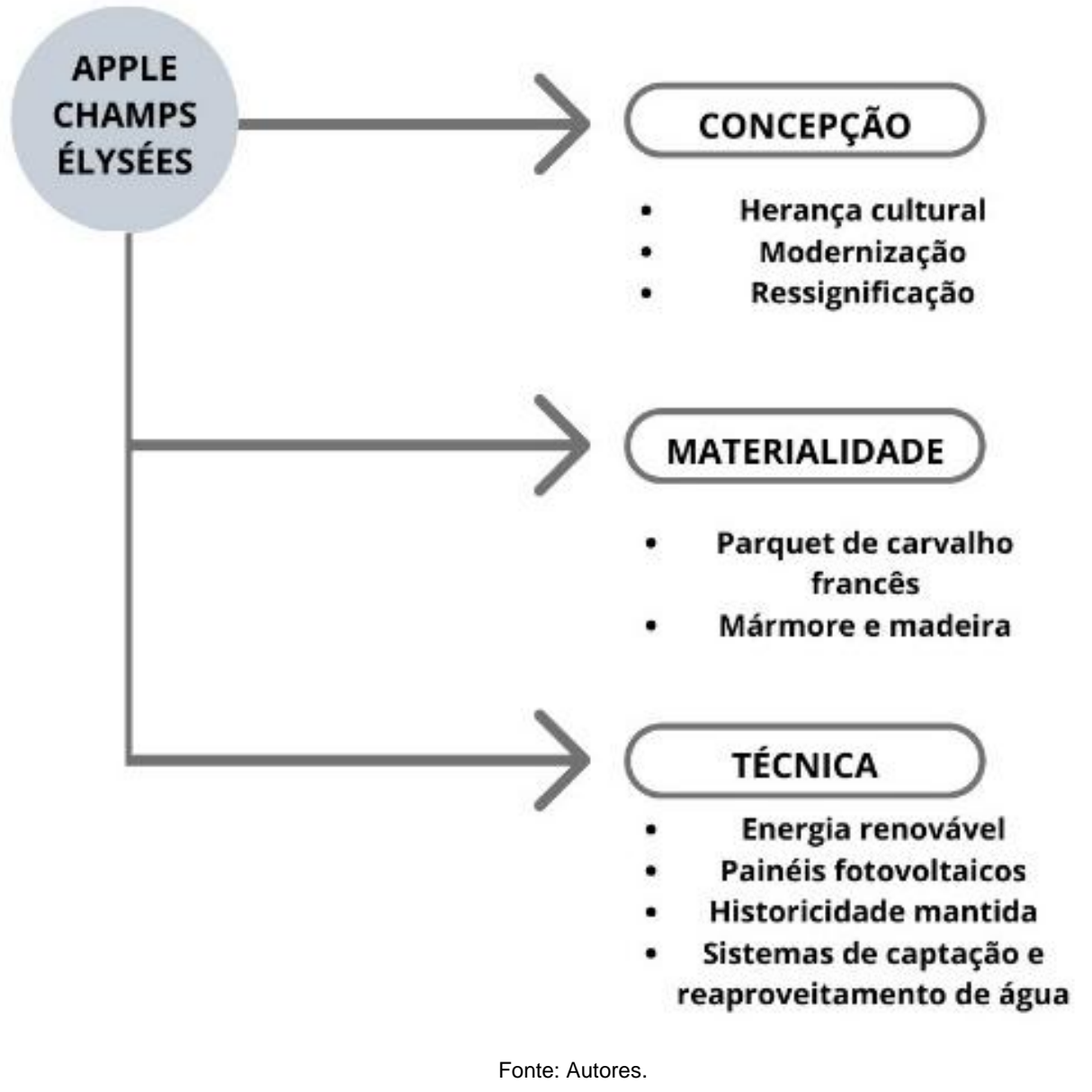

\section{Conclusões}

Não diferente e obstante ao século passado, a tectônica segue seu curso e atualização no século $\mathrm{XXI}$, alicerçada nos estudos e reflexões de diversos autores. Tem se mostrado campo fértil como abordagem e ferramenta interpretativa na arquitetura da contemporaneidade, sobretudo no que concerne a atualização do conceito voltada à sustentabilidade e tecnologia.

No presente artigo, ambos exemplos recortados para breve aplicação da teoria, pautada nas principais esferas de análise arquitetônica (conceito, materialidade e técnica), servem de reflexão quanto aos mecanismos intrínsecos da projetação. Estes, por sua vez, se bem concatenados e alinhados, são capazes de elevar o status da obra, conduzindo a 'poética da construção' a novos caminhos do século atual.

Os edifícios abordam uma só funcionalidade, uma só tipologia espacial, e, apesar de estarem em contextos culturais distintos (Estados Unidos versus União Européia), são capazes de elucidar diretrizes necessárias e importantes em projetos de reabilitação cada vez mais crescentes no contexto urbano contemporâneo. Contexto este que, no caso dos exemplos das lojas da Apple, anseia por novas relações comerciais, novos posicionamentos comportamentais do indivíduo frente aos edifícios, novos valores frente a uma nova era, mais tecnológica, mais rápida e ágil, mais conectada. E o que seria a função da arquitetura senão atender às novas demandas, em face o respeito ao passado, resposta ao presente e busca pelo futuro?

Nos estudos de caso selecionados, é evidente que o escritório de Foster + Partners perpassa as esferas de concepção, da materialidade e da técnica, com foco nos processos de manutenção e reabilitação do patrimônio com a associação do material, da forma, da função e da estética, 
aliando a preocupação às questões da sustentabilidade como a possibilidade de manter a arquitetura aberta à constante possibilidade de modificação.

Percebe-se que as duas edificações expressam soluções inovadoras no processo de revitalização de edifícios, com respeito aos significados e heranças culturais das obras, com cuidado na preservação do antigo e na expressão do novo, na forma em que novas tecnologias foram aplicadas e a preocupação com as futuras gerações na maneira de projetar o espaço numa perspectiva sustentável, tendo em vista os atuais problemas ambientais que a sociedade enfrenta.

Em resumo, na contemporaneidade, pensar a cidade como um organismo vivo e dinâmico por meio de uma arquitetura resolutiva e operativa torna-se necessário, especialmente no que diz respeito à preservação do patrimônio, com fins de preservar o valor histórico de uma edificação ao mesmo tempo que a reabilita. Para tal, a tectônica tem se mostrado e mantido em posição capaz de mediar as relações com o patrimônio, meio ambiente, soluções inovadoras e tecnológicas e, acima de tudo, respeito aos diferentes contextos urbanos, permitindo maiores possibilidades na identificação do processo de projeto voltado às demandas atuais. Seria então a tectônica a 'tábua de salvação' para a arquitetura contemporânea tanto em projetos de reabilitação quanto em novos projetos? Não... apenas um possível caminho.

\section{Referências}

BÖTTICHER, Karl Gottlieb Wilhelm. Die Tektonik der Hellenen, Volume 1. Potsdam: Berlag von Ferdinand Riegel, 1852 (Reimpressão do original pela Nabu Public Domain Reprints).

CANTALICE II, Aristóteles de Siqueira Campos. Descomplicando a tectônica: três arquitetos e uma abordagem. 2015. 305 pg. (Pós-graduação em desenvolvimento urbano do Centro de arte e Comunicação) - Universidade Federal de Pernambuco, Recife, 2015.

COLLINS, Peter. Concrete: the vision of a new architecture. London: McGillian books, 1959 [2004].

DEPLAZES, Andrea. Constructing Architecture: Materials, Processes, Structures. Boston: Birkhauser, 2005.

Making Architecture. Zürich: ETH, 2010.

Foster + Partners. Apple Carnegie Library, 2019. Disponível em: https://www.fosterandpartners.com/projects/apple-carnegie-library-washington-dc/. Acesso: Dezembro 2019.

Foster + Partners. Apple Champs Élysées, 2018. Disponível em: https://www.fosterandpartners.com/projects/apple-champs-elysees/. Acesso: Dezembro 2019.

FRAMPTON, Kenneth. Studies in Tectonic Culture. Cambridge, Massachusetts: The MIT Press, 1995.

GREGOTTI, Vittorio. Los materiales de la proyectación. 1966. In Teoria de la Proyectación Arquitectonica. Barcelona: Ed. Gustavo Gili, 1968, p.209-241.

O Exercício do Detalhe. 1983. In NESBITT, Kate (org). Theorizing a new agenda for architecture: an anthology of architectural theory, 1965-1995. Princeton: Princeton Architectural Press, 1996, p.535-538.

MAHFUZ, Edson. Ensaio sobre a Razão Compositiva, uma relação do todo com as partes na arquitetura. Rio Grande do Sul: UFRGS, tese de Doutorado, 1995.

MÜLLER, Karl Otfried. Ancient and its remains; a Manual of the archeology of art. London: A.Fullarton and Co. Newgate Street, 1830 [1850]. 
SEKLER, Eduard. Structure, Construction, Tectonics (1964). In KEPES, Gyorgy. Structure in Art and in Science. New York: George Brazilier, 1965, p.89-95.

SEMPER, Gottfried. The Four Elements of Architecture (1851). In MALLGRAVE; HERRMANN [org.]. The Four Elements of Architecture and Other Writings. Cambridge: Cambridge University Press, 1989. 